\title{
Computer Dictionaries and Encyclopedias in Teaching English as a Second Language
}

\author{
Damira Jantassova, Safura Zhilkishenova and Elena Klukina
}

\begin{abstract}
The objective of this paper is to explore one of the aspects of the problem of the use of information communication technologies in English as a Second Language teaching and learning. There has been studies on the effectiveness of computer dictionaries and encyclopedias in teaching and learning English language as well as the attitude of school English teachers to the application of computerbased inquiry software that are considered to be new in Kazakhstani comprehensive education. This article argues that computer dictionaries and encyclopedias contribute to development of English language learning by providing a teacher and a learner with a didactic tool for free access to a variety of materials, comfortable information search opportunities, and communication as well. The study that was conducted in Karaganda city high school, Kazakhstan, shows that the computer dictionaries and encyclopedias motivate school students to learn English language more enthusiastically.
\end{abstract}

Key words: computer-based inquiry software, hypermedia, language skills, experimental teaching

\section{Introduction}

Teaching English as a Second Language is highly influenced by development of the contemporary information communication technologies, which are considered to be a broad term referring to the use of technology in language communication paradigm. Having explored the experience of computer technologies application in ESL teaching, our research has appeared to be of great importance for Kazakhstani English language compulsory education.

ELT scholars worldwide discuss how to become a modern highly-qualified English teacher. There is a focus on making the learning process integrate multiple language skills, enhancing cognitive activity and choosing individual learning strategies, which would be applicable and reliable to a certain group of school students. Moreover, as Russian scholar Polat says, teachers need to develop learners' ESL potential and individual learning creativity (Polat, 2001, pp.10-14). And in order to realize the above mentioned ideas in ESL teaching, there is potential in the use of computer language software because it significantly enhances the learning process.

The study of the use of computers in learning and teaching languages in the broadest sense, from the use of word processors to the use of the Internet, is known as computer-assisted language learning (CALL) (Warshauer, 1996, pp.3-9). CALL has been defined as "the search for and study of applications on the computer in language teaching and learning" (Levy, 1997, p.1) and is now used in a variety of instructional situations. Chapelle (2001) reported that the use of the term CALL for computers in language learning was agreed on by early practitioners who met at the 1983 Teachers of English to Speakers of Other Languages (TESOL) conference. Many international researchers strongly emphasize the significant role of CALL in developing linguistic proficiency and communicative competence in ESL learners as well as promoting increased levels of learner autonomy (Galavis, 1998, pp.27-35). 
The use of computer-based reference software such as dictionaries, encyclopedias and web references contributes to learner-centered approach in language teaching, provides teaching with differentiation in accordance with children abilities and inclinations, forms firm motivation towards language learning, and optimizes the process of English language comprehension (Nesterova, 2005, p. 102-103). The study we conducted examined some advantages of computer-based inquiry software in ESL learning and its applicability for Kazakhstani school system.

Based on the high interest of many researchers and practitioners (Siennicki, 2006, p.198-207; Keser, 2009, p.104; Wei-Yuan Lu, 2009, p.108; Bovtenko, 2005, pp.156-178; Oates, 2006, pp.2364-2366 and others) in using computer dictionaries and encyclopedias and didactic functions of this kind of software we state the research question - Do computer dictionaries and encyclopedias improve the process of teaching and learning English as a second language? In this way we need to make clear what this computer-based inquiry software is.

The majority of "paper" dictionaries are focused on the person who reads in English, the person who finds the basic words that help to build the general semantic meaning. The English written speech, except the knowledge of all used words, demands precise representation how these words are combined with each other, what prepositions are used, and whether the expressions transfer appropriate sense. And if the "paper" dictionary satisfies the needs of a reader, it more often ignores the interests of a writer who writes in English as a foreign language. Moreover, today in our century of electronic communications each user of the Internet has practically become a writer.

Thus, the teacher of foreign language using different information technologies at the lessons, sooner or later will have come to conclusion that paper traditional dictionaries mismatch the reality frequently. The main reason of it is that actually many dictionaries, which were generated in a language atmosphere of the middle of the century, have strongly become outdated. Modern values of old words are not specified and many new words are absent (Bovtenko, 2005, pp.156-178). Copying "paper" dictionaries on computer base is unpromising. It became especially obvious in connection with development of a global network - the Internet: the most part of Web-pages consists of the English texts written by the up-to-dated language, plentifully using colloquial lexicon and slang. Hardly any of the existing English-Russian or English-Kazakh dictionaries can answer these needs. Only electronic dictionaries can solve this problem as it is proved by everyday multiple addresses of learners and teachers to the online dictionaries such as "Multitrun", "Abby lingua", "Promt” and others.

\section{Research context}

\section{Electronic dictionaries}

There is a wide range of electronic dictionaries, on which teachers' eye might focus on. But we have paid our attention on bilingual English-Russian and Russian-English dictionaries. The most known and used computer dictionaries are electronic translator "PROMT", computer dictionary "Lingvo" of companies Abbyy and MultiLex developed by firm "MediaLingua". It is curious for us to compare these dictionaries as they have different sights on principles of the electronic lexicography.

Travel of students to the world of computer linguistics begins with the main page of PROMT Professional 7.0 - electronic translator PROMT. The PROMT dictionary is focused on the work of Microsoft Office, browser Internet Explorer, emailing program Microsoft Outlook and such document as Adobe Acrobat Reader. The tool panel of PROMT is built with the abovementioned programs and allows executing text translation directly in the window of the application, not leaving it, that saves time of students in creation and protection e-mail projects. The system of the dictionary has more than 1,000,000 words and word-combinations on a variety of topics. Using this electronic dictionary for the purposes of teaching and learning a foreign language - quick translation of the text including graphic files, content of e-mails and web sites connected to the Internet - will cease to be the difficult problem that requires great time 
expenses and will turn to be habit for ESL students (Zelzer, 2002, p. 97-103).

The company MediaLingua keeps the simple strategy on creating dictionaries "MultiLex" (http:// online.multilex.ru/). It creates a digital copy of known book editions. The rigid binding to the paper prototype does not give an opportunity to correct and supplement electronic version of dictionary, especially to change structure of construction of the entry.

It might be said with the confidence that electronic dictionary "ABBYY Lingvo" is the fullest dictionary nowadays. The last $11^{\text {th }}$ version includes 46 dictionaries: general, thematic, explanatory and phrase books. They contain 2,300,000 entries (more than 7,000,000 translations) by means of which students can quickly receive correct translation of any word and the accompanying information about it: a transcription, examples of the using, synonyms, interpretation and grammatical characteristics. Each word is sounded by the native speaker that allows training pronunciation skills in the class as well as out of the class. Besides the English-Russian dictionaries, "ABBYY Lingvo" contains German, Spanish, Italian and French dictionaries that allows working with words in six languages and making the comparative analysis inside of this or that language group.

But the basis of "Lingvo", according to the Head of the Linguistic Department of Vladimir Selegey's Company, is created by non-native speakers. Each new version of "Lingvo" is supplemented with the updated vocabulary, where mistakes and discrepancies are corrected. Thus, owing to lexicographic researches the English-Russian dictionary of company "ABBYY" is close to a native language practice. That allows adapting the process of foreign languages teaching to the real world.

\section{Encyclopedias}

Using the computer encyclopedias in ESL teaching and learning is considered to be one of the perspective tendencies nowadays. Wikipedia is the multilingual popular freely distributed encyclopedia which is published on the Internet and let out in format of DVD. It is created in many languages of the world by collective work of voluntary authors.
From the moment of origin in the beginning of 2001 and until now Wikipedia has been steadily growing and getting popularity among users of the Internet.

Unlike traditional encyclopedias, Wikipedia is based on hypertext. The hypertext is a system for the nonsequential presentation of text, the fundamental concept of the World Wide Web, whereby the user can jump from one part of a text to another, from one Web page to another, or from one website to another, by clicking on underlined hyperlinks that are known as a reference to a document that the reader can directly follow, or that is followed automatically. The concept of hypertext predates the Web by many years. Vannevar Bush is credited with inventing the concept of hypertext in his article "As we may think", which was written as early as 1945 and describes an imaginary machine called "Memex (a portmanteau of "memory" and "index")" - essentially a hypertext device that takes account of the way the human mind associates ideas and follows a variety of different paths rather than moving on sequentially.

The hypermedia is the extension of the hypertext to multimedia, describing the combination of multimedia information (text, images, audio, video, etc.) in a meaningful configuration which is especially useful for teaching and learning (Doncov, 2007, p. 72-73) Using the hypermedia technology meets such requirements shown to encyclopedias as structure, convenience in circulation. If it is necessary the material can be corrected easily. Now there is a set of various hypertext formats (HTML, DHTML, PHP, etc.) which one of the world-used online encyclopedia known as "Wikipedia" is based on.

Wikipedia resources can be effectively used in teaching and learning English in class and out of the class activities as well as in planning a lesson by a teacher of foreign language, in selection of the authentic material, etc. It is confessed by many language teachers that the help of encyclopedias is valuable for development of all language skills (Steven, 2001, pp.44-47).

So, having studied different teaching experiences we can say that it is useful to integrate informational resources of computer encyclopedias in educational process to solve a lot of didactic problems at the lesson more effectively: 
- to develop reading skills directly using and adapting materials of the Wikipedia of a different language level;

- to improve listening comprehension skills on the basis of authentic sound texts of the encyclopedia adapted by the teacher to the learning process;

- to improve writing skills, answering to partners' questions, participating in preparation of reports, compositions, other epistolary products of joint activity of partners;

- to enlarge the vocabulary, both active and passive, of the current foreign language that reflects a certain stage of development of culture of people, social and a political system of a society;

- to get acquainted with culture that includes speech etiquette, features of speech behavior of various people, traditions of the country;

- $\quad$ to form steady motivation to ESL learning.

\section{Pre-study questionnaire on teachers' views on computer inquiry software application}

In the frame of pre-study with the aim of presenting the real picture of using computer dictionaries and encyclopedias by ESL teachers, there has been made the questionnaire among school English teachers of Karaganda city, Kazakhstan. In order to study effectiveness of computer-based inquiry software we believe that it is necessary to get to know the English teachers' attitude to this kind of technology and their way of using them in teaching at schools. So that the main tasks of the questionnaire were

- to reveal the awareness of teachers about existence of computer dictionaries and encyclopedias and the attitude to their use;

- to examine the frequency of their using at English lessons;

- to know what activities the English teachers used to have by applying computer dictionaries and encyclopedias in class;

- $\quad$ to study the challenges have been appeared in the use of computer dictionaries and encyclopedias in English class.

The questionnaire consists of twelve open questions where high school teachers wrote their answers. The results of questionnaire are shown at the Diagram A where $57 \%$ of the respondents consider that the modern teacher refuses to use the ready course books and prefers to teach current English that is presented with the help of ICT. The teachers are well informed about the kinds of computer dictionaries and encyclopedias, about their work principles, and mostly they prefer using network encyclopedias for lesson preparation and out-of-class learning. They strongly believe that using ICT in ESL teaching and learning has been increasing motivation of students to foreign language learning.

Thirty five percent of the respondents prefer to build the work on a principle of traditional methodology, that is to say they know about existence of computer dictionaries and encyclopedias because of the problem of insufficient financing to the ICT support which leads to absence of constant access to resources of the encyclopedia and the dictionary.

The last $8 \%$ of the respondents use the computer dictionaries and encyclopedias for self-directed language learning to provide the students with the opportunity to study English individually as this kind of computer inquiry software allows developing language skills with self-control functions.

\section{Diagram A}

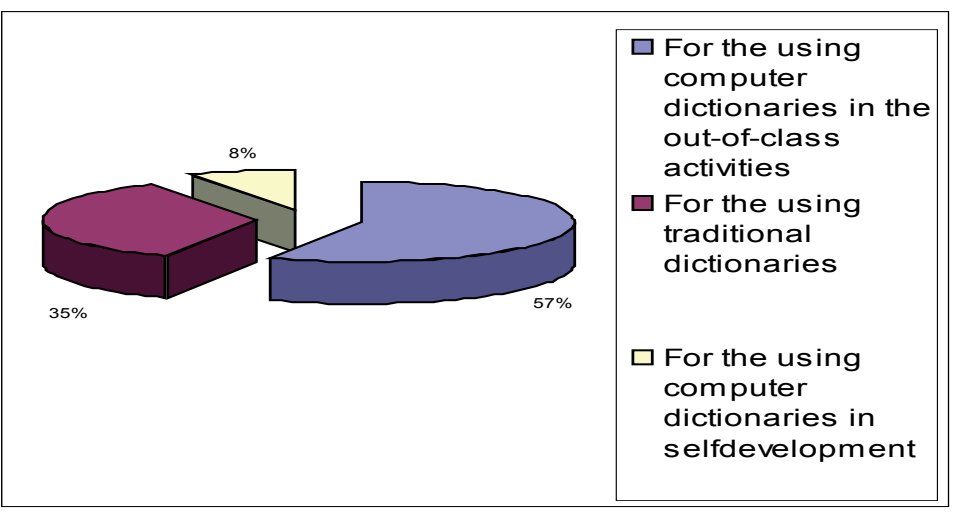

Moreover, having based on teaching experience the majority of the teachers emphasize in the answer sheets that the computer-based inquiry software plays the important role in foreign language teaching and learning and have a number of advantages in contrast to traditional methods: 
- it raises the level of English Proficiency and computer usage;

- it keeps developing of motivation to language learning;

- it realizes the principles of self-directed language learning.

So, here we can see that teachers are aware of advantages of computer-based inquiry software from their own teaching experience at schools and it helped us to conduct the main study of the research.

\section{The study}

With the purpose of exploring the effectiveness of the computer dictionaries and encyclopedias there the experimental teaching in $10^{\text {th }}$ grades of the Karaganda high school was conducted. The number of participants was 40 where the 10 "a" class was an experimental group and the 10 "b" class - control group. The main criteria of selection of participants of the experiment were level of English Proficiency, level of computer literacy and age. So, to identify the level of English there has been presented the pretest that consists of three stages: grammar-vocabulary test, listening comprehension tasks and speaking on the curriculum topics. The age of the participants was 16 years old. It was agreed to use computer dictionaries for in-class activities and computer encyclopedias for out-of-class work in ESL teaching in a short-term view.

In the frame of the main objective of the research the main tasks of experimental teaching were the following:

- to teach school students to work with electronic dictionaries and translation systems;

- to teach school students to study English with the help of computer dictionaries;

- to lead the comparative analysis of work with traditional and computer dictionaries;

- to conclude the result and offer the recommendations.

The criteria of the estimation of the experimental teaching have been allocated the time, during which students would be making the tasks; the speed, with which work would have been done and the correctness of results of the done assignments. The teaching and learning process has been researched in two high school classes, in which in one class there was teaching with the use of traditional dictionaries and in another one - the use of computer dictionaries. The experiment lasted a half of one school term (one month).

The task that was given to the students was to practice the new lexical units on the module: "What do you like?", "What's best in your country?"; to listen and to comprehend the content of the texts translating with use of the dictionary "Lingvo" and speak on the topic using the studied words and word expressions. At the lessons there has been used the multimedia base of the interactive whiteboard (IWB), which is known as a touch-sensitive projection screen that allows the teacher to control a computer directly by touching the screen. The IWB is a convenient modern tool for effective academic purposes, business presentations, and seminars. It not only combines advantages of the big screen and marker boards, but also allows to keep all marks and the changes made during discussion and even to operate computer applications, not interrupting performance and providing access to resources of the Internet.

The results of the experimental teaching are reflected in Tables 1, 2 and show that the quality of learning with the use of computer dictionary "Lingvo" is much high than the quality of learning with the use of traditional dictionaries, that is presented in the Diagram B.

\section{Table 1: Indexes of the quality of the}

learning progress of the 10 " $a$ " class

\begin{tabular}{|c|c|c|c|}
\hline $\begin{array}{c}\text { Week } \\
\text { number (2 } \\
\text { lessons a } \\
\text { week) }\end{array}$ & $\begin{array}{c}\text { Respon- } \\
\text { dents } \\
\text { number }\end{array}$ & $\begin{array}{c}\text { Respondents } \\
\text { number who } \\
\text { got excellent } \\
\text { and good } \\
\text { marks }\end{array}$ & $\begin{array}{c}\% \text { of the qual- } \\
\text { ity of students' } \\
\text { progress }\end{array}$ \\
\hline 1 & 20 & 11 & $55 \%$ \\
\hline 2 & 20 & 15 & $75 \%$ \\
\hline 3 & 20 & 14 & $70 \%$ \\
\hline 4 & 20 & 17 & $85 \%$ \\
\hline Total & & & $71 \%$ \\
\hline
\end{tabular}


Table 2 «Indexes of the quality of the learning progress of the 10 "b" class"

\begin{tabular}{|c|c|c|c|}
\hline $\begin{array}{c}\text { Week } \\
\text { number (2 } \\
\text { lessons a } \\
\text { week) }\end{array}$ & $\begin{array}{c}\text { Respon- } \\
\text { dents } \\
\text { number }\end{array}$ & $\begin{array}{c}\text { Respondents } \\
\text { number who } \\
\text { got excellent } \\
\text { and good } \\
\text { marks }\end{array}$ & $\begin{array}{c}\% \text { of the qual- } \\
\text { ity of students' } \\
\text { progress }\end{array}$ \\
\hline 1 & 20 & 7 & $35 \%$ \\
\hline 2 & 20 & 9 & $45 \%$ \\
\hline 3 & 20 & 11 & $55 \%$ \\
\hline 4 & 20 & 9 & $45 \%$ \\
\hline Total & & & $45 \%$ \\
\hline
\end{tabular}

\section{Diagram B «Comparative analysis of the quality of learning in the group 10 " $b$ " and group 10 " $a$ " "}

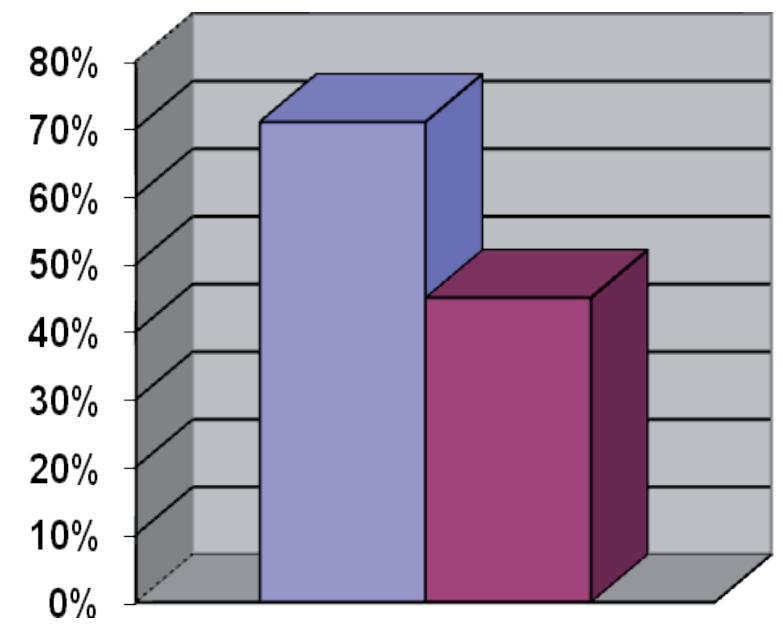

the language material. It is necessary to note the shortening of time in doing tasks, and also in deleting a gap between, so-called, "strong" and "weak" students. It was observed that there was a great interest of the weak students thanks to study with the use of computer dictionaries. It was found out that it reduced probability of duplication of students' answers while translating and develops a language guess in selection of a suitable word equivalent.

Thus, using of computer dictionaries at the foreign language lessons is one of the relatively new means of raising pupils' motivation to foreign languages learning, developing of self-directed work of pupils and multilingual perception of language units.

The research on the determination of the role of Wikipedia has been realized with the same tenth grade students. The task given to $\square 10$ "a" the students, which was out of$\square 10$ "b" class activity, was to expanding the students' knowledge in the frame of cultural aspect of foreign language learning. The lesson was organized in the form of the game and devoted to a theme "The United Kingdom of Great Britain and Northern Ireland”.

The qualitative and quantitative analysis of the experimental teaching with the use of computer dictionaries suggests that the time spent by the students of the experimental group on doing tasks is less than that of the control one. The speed of learning materials is higher in experimental group than in the control one, and the correctness of answers more often corresponds to the sample. The criteria of assessment allow judging a degree and quality of developed skills of the students.

The use of the computer dictionary in educational process allows expanding the borders of the traditional lesson where the students are in direct contact with the teacher and get necessary support only from him, but also promotes to increase of the students' interest to independent work with
The analysis of work with Wikipedia in out-of-class activity allows defining the great role of Wikipedia materials, which are authentic, and that is highly important for language learning. During the activity there were being involved four language skills: listening and reading comprehension skills, speaking and writing skills as well. There were the following tasks with texts taken from the computer encyclopedia: finding the main idea, analysis, annotation, synthesis and compression of the information, development of grammatical terminology, translation of texts from English to Russian.

\section{Conclusion}

In the research the learning value of the computer 
dictionaries and encyclopedias in ESL learning has been proved during experimental teaching and many advantages of ESL teaching with their use have become obvious.

The use of the computer dictionaries and encyclopedias not only diversifies the educational process, it also opens great opportunities for expansion educational frames, bears significant motivational potential, and promotes realization of individual teaching principles. It allows increasing of the amount of self-directed learning and individual correction in processes of skills formation that subsequently improves the quality of foreign language learning as a whole.

Working with computer dictionaries school students have an opportunity to

- increase a speed of unfamiliar word searching;

- search word-combinations, words with incorrect spelling;

- $\quad$ use the means of multimedia for vocabulary learning;

- use hyperlinks;

- track the actions.

Resources of the computer encyclopedias in teaching and learning process are considered to be useful topic-based language materials that are easy to include in out-of-class ESL activities. The results of our research demonstrated the fact that students have successfully developed the reading comprehension and writing skills as they have had access to up-to-dated and fresh topic-based materials for reading activities and producing a variety of written works.

The doubtless advantage of information resources of electronic dictionaries and encyclopedias is the big emotional impact on students of high school. Now with the full confidence it is necessary to say that this kind of computer technologies influences strongly on the whole educational process.

As a result of the research aimed at determination of the role of computer dictionaries and encyclopedias, we offer following recommendations for the organization of in-class and out-of-class teaching and learning with the use of the computer dictionaries and encyclopedias:

In order to bring the use of the computer dictionaries and encyclopedias to the level of free manipulation firstly teacher should give introduction course to students;

In order to cover all vocabulary and save the time for searching the suitable equivalent teacher needs to create his own dictionary that includes the lexical units of the lesson;

For the development of students' English learning autonomy based on the use of the computer dictionaries and encyclopedias teacher needs to present the language materials by using multimedia technologies in order to cover students' personal characteristics.

Damira Jantassova is a senior teacher at the Department of ESL teaching at the Buketov Karaganda State University, Kazakhstan. She trains pre-service English teachers and supervises students teaching practice at schools and students' research projects as well. Her research interests are computerassisted language learning, teacher education and distance language learning. She has more than thirty publications including articles in a variety of journals such as Educational Media International (Austria), SITE 2006 Proceedings (USA), and Vestnic KarGU (Kazakhstan), the tutorial "Practicum on the use of language software in learning English", and two computer learning programs, "Distance language learning" and "Computer-assisted language learning". She is President of National Association of Teachers of English of Kazakhstan (NATEK) and member of TESOL and CALICO.

Safura Zhilkishenova is a teacher at the Department of ESL teaching at the Buketov Karaganda State University, Kazakhstan, the second year graduate student of master degree course on ESL. Her research interests are the use of computer-based inquiry and software in teaching English.

Elena Klukina is a senior teacher in the Department of English practice at Pyatigorsk State Linguistic University, Russia. She is interested in teaching ESL with the use of computer technologies in extracurricular work. She teaches preservice English teacher as well as interpreters courses like "English for Specific purposes" and "Theory and practice of interpretation".

\section{Reference}

Warshauer, M. (1996). Computer-assisted language earning. In S. Fotos (Ed.), Multimedia language teaching. Tokyo: Logos International, p.3-9;

Polat, E.S. (2001). Internet on the foreign language lessons. Moscow, Russia: Moscow University Press. 
Levy, M. (1997). Computer-assisted language learning: Context and conceptualization. New York: Oxford University Press.

Galavis, B. (1998). Computers and EFL class: Their advantages and a possible outcome, the autonomous learner. FORUM, Volume 36, Number 4, $p$ 27-35.

Chapelle, C. (2001). Computer applications in second language acquisition. Cambridge, England: Cambridge University Press.

Nesterova, N.V. (2005). Informational technologies in English language teaching. Moscow, Russia:Moscow University Press.

Barbara S. (2006). Pronunciation Power 1-8 in 1 Dictionary. CALICO Journal Volume 24, Number 1. - p. 198-209.

Hafize, K., \& Serkan, C. (2009). Research on data-driven learning: concordances vs. dictionaries. TESOL program book. - p.104.
Wei-Yuan, L. (2009). Monolingual/Bilingual online dictionaries affect vocabulary acquisition of ESL learners. TESOL program book.- p.108

Bovtenko M.A. (2005) Computer lingua-didactics. Research edition. - Moscow: "Флинта": Science, p. 216.

Oates, R., Hartman, S., \& LeBlanc, P. (2006). E-booksin Higher Education. SITE proceeding book. -p.2364-2366.

Doncov, D. (2007) English language on the computer. Sankt-Petersburg, Russia: Peter Press;

Zelcer, D. (2002) What can dictionaries? SanktPetersburg, Russia: Peter Press;

Steven, D. (2001) Adapting authentic materials for language teaching. Washington, USA: "Forum" Press. 